\title{
De Brasilio a Antonio de Alcantara Machado (*)
}

Meus caros confrades.

Esta palestra é duplamente agradavel para mim, porque a faço num ambiente de camaradagem, entre velhos e queridos companheiros de luta. Trago como thema dois nomes que me são carissimos. Se a linguagem do coração vale é ella que utilizo agora para me referir a Brasilio e a Antonio de Alcantara Machado, no senaculo illustre da imprensa de S. Paulo.

Ambos foram jornalistas, seguindo o rumo natural de todas as intelligencias emotivas de nossa época. $O$ immenso Chesterton, pouco antes de morrer, dizia que já não temos mais prosa e verso, e sim jornalismo. De facto, é elle que define bem as linhas caracteristicas de nosso tempo. Aspecto da vida no seculo passado, cresceu monstruosamente com o industrialismo e tornou-se esta formidavel e impressionante agitação de nosso seculo. Hoje em dia, exige organização especial, rigorosa distribuição de funcções technicos para todos os assumptos e, dentro de tudo isso, um irriquieto senso de opportunidade. O jornal não é mais um recanto da intelligencia, um pedaço de sonho borboleteando por aqui ou por ali. E' uma força poderosamente decisiva, a vida social vivendo na consciencia de todos, na sensibilidade de todos. Quando elle sáe de manhã, mal desapparecem as sombras da noite ou quando sáe á tarde, mal o trabalho diurno começa a perder a sua intensidade, é curioso

(*) (Conferencia realizada na A. P. I. pelo livre docente Professor Dr. Candida Motta Junior, em Janeiro deste anno). 
o vêr-se a capacidade de infiltração e de socialização que exerce. $O$ povo tem sêde de noticias, tem fome de noticias. Tudo aquillo que interessa ao homem moderno, desde as cotações nos mercados, os movimentos bancarios até $o$ annuncio humilde de uma cozinheira, o jornal fixa e anima, com inegualavel soffreguidão democratica. E ao abrirmos um jornal, cheio de noticiario, de suggestões e de annuncios, o mundo apertando-se em suas columnas, com suas guerras, revoluções, disturbios, terremotos, construcções, inventos, festas, politica, protestos, esportes, divertimentos, podemos tirar uma conclusão muito significativa em nosso seculo. Se a democracia falha, em grande parte, com a crise da representação e com a crise de parlamento, a democracia se realiza, apezar das compressões em contrario, pela imprensa.

Quem abre um dos grandes jornaes americanos verifica, de relance, que elles reflectem exhuberantemente a vida vivida. Os europeus nem se fala. Cada pagina cheia dá a exacta impressão de exhuberancia social. A potencia politica do jornal decorre disso, em grande parte. Penetrando nas classes ricas e penetrando nas classes pobres e estando, com a rapidez do transporte moderno, em varios pontos ao mesmo tempo, elle exerce, sem duvida, a mais poderosa influencia social de nossa época!

Entre nós, porém, essa influencia tem um aspecto especial, influencia que foi exactamente comprehendida por Brasilio Machado e por Antonio de Alcantara Machado. 0 jornalismo patricio atravessa ainda por um periodo heroico, que os historiadores denominam o periodo de conquista. Um jornal, na soalheira tropical de nossos sertões, é uma caravana que investe, audaciosa e petulante, para o desconhecido. Num paiz ainda em plena edificação economica, onde o homem, no dizer de Alberto Torres, não póde affirmar se é rico ou pobre, porque não conhece a sua terra, o jornalismo é ainda o desassombro da intelligencia, a devoção da intelligencia. Desde os prodomos da independencia até nossos dias, o jornalismo brasileiro, passando por 
crises explicaveis, não variou ainda em seu significado inicial. A leitura dos pamphletos dos tempos de Pedro I, o estudo do jornalismo de Evaristo da Veiga leva-nos a concluir que o jornalismo, no Brasil continua com a mesma missão, muito embora, hoje em dia, tenha outras condições para viver e para vencer. Como no dealbar de nossa independencia, é uma força creadora, um esforço de abridores de caminho, empenhado assim a formar o espirito collectivo, a fomentar a comprehensão dos valores culturaes, a transformar as lutas politicas, exacerbadas e muitas vezes ferozes, numa campanha impressionante e ponderada. Na incerta e movediça sociedade nacional, onde o esforço individual, onde a defesa dos interesses collectivos exige esfaltantes sacrificios - o jornal é a melhor arma que combate com vantagem esse estado de coisas. Na velha Europa ensanguentada, estão os preconceitos empedernidos, seculos de convenções indestructiveis. $\quad 0$ nosso jornal encontra um mundo novo germinando, o espirito de aventura, a tendencia para improvização, a rebeldia, a docilidade, aquillo que foi hontem e que não é mais hoje.

Diante disso, o jornalista ou constróe ou desapparece. Não póde ser elle o homem de negocios, o ajuntador cuidadoso de moedas. Sem grande dóse de ideal, nada faz. Assim para as redacções dos jornaes vão os desprehendidos e sonhadores, como foram Brasilio Machado e Antonio, o avô e o neto, - os dois, cada um em seu tempo, honrando e illuminando a imprensa de S. Paulo.

Foram jornalistas nessa larga e desinteressada funcção cultural, por entre a expontanea e explicavel desconfiança do meio em que viveram. Debateram os grandes problemas, agitaram os grandes themas, focalizaram attitudes e rumos e de tal modo que, para mim, foi pelo jornalismo, que Brasilio Machado e Antonio de Alcantara Machado mais fizeram pela sua terra e pela vida espiritual de sua gente. 


\section{O BARÃO BRASILIO MACHADO}

foi um dos maiores advogados do Brasil. Jurista insigne, mestre de Direito, foi, por tudo isso, uma das figuras mais expressivas do scenario intellectual de São Paulo.

Conheci-o ligeiramente e a impressão que delle guardo é ainda a impressão de criança. Brasilio Machado era o homem que sabia falar e que falava com tal encanto que. como a flauta do pastor arabe, abria o ferrolho das prisões mais fechadas! O magnifico principe da tribuna judiciaria nunca soffrera uma derrota e até hoje seus discipulos guardam embevecidos, a impressão de seus discursos. Tinha um assombroso senso de opportunidade, uma extraordinaria presença de espirito, uma admiravel agilidade mental. Recebia as objeccões com antecipada certeza de refutal-as. E fascinava então o auditorio, como o yapurú no mattagal do norte.

Com essa força espiritual e com esse poder de convencer, foi um jornalista victorioso e frequentou suas columnas com o mesmo garbo com que frequentou a tribuna judiciaria e a cathedra da velha Faculdade de Direito.

O neto admirava esse avô extraordinario e dizia-me a mim mostrando-me o arquivo de Brasilio Machado, numa tarde de deliciosa palestra literaria, que era de seu intento, algum dia, viver-lhe a vida, escrevendo-lhe a biographia.

O jornalista que, de inicio, se revelára com qualídades excepcionaes, tinha uma feição pouco commum entre nós: - formação philosophica. Em regra, somos um povo sem ponto de vista. Sentimentaes e imaginosos, credulos na epiderme, septicos nas entranhas, vamos pensando e sentindo ao sabor da corrente. Brasilio Machado tinha uma visão do mundo. Norteava sempre o seu pensamento director. Por isso, não foi propriamente um politico e por isso mesmo fez, na imprensa, obra profunda e interessante. Como começou em Piracicaba, permaneceu até morrer. A Republica que elle viu nascer e progredir, agitou-se deante de seus olhos. Mas, os erros da Republica só serviram para robus- 
tecer suas velhas convicções. Mesmo suas travessuras na imprensa, traçadas no "Etupéva”, com Moraes Barros, já definiam o estylo de seu caracter e o estylo de sua penna.

Em Piracicaba, onde viveu intensamente, foi, de, facto, onde iniciou, em 1874, a sua actividade de jornalista, uma actividade fóra do commum, propria de uma personalidade incapaz de se submetter á tranquilla paz dos burgos do interior, á vida marcada pelas carambolas nos bilhares dos clubes, nas conversas das portas de pharmacias ou na contemplação inutil dos repuxos, no jardinzinho publico, nas tardes estivaes.

Brasilio Machado, homem de luta, precisava de horizontes mais largos. Appellou para o jornal onde encontra sua vocação. E, se começou em 1874, no "Piracicaba", collaborou depois em varios jornaes paulistas e do paiz, taes como o "Correio Paulistano", "A Ordem", "O Ypiranga", “A Tribuna Liberal”.Mas, não só collaborou em varios jornaes, como dirigiu varios outros, com paixão e intelligencia "A Constituinte" "O Diario da Manhã", “A Tribuna Liberal", "O Liberal Paulista", "O Federalista", tendo afinal dirigido - "S. Paulo" Fundou "A Patria", orgão da Federação Catholica e tambem a "Santa Cruz", que até hoje vive.

Enorme, portanto, sua actividade na imprensa. Não fez, jamais, obra de diletante, o jornalismo vaidoso, que contitue uma das pragas dos jornalismo. Fez jornalismo em si, o jornal pela missão do jornal. Em 1893, Brasilio Machado escrevia: - "A imprensa foi sempre uma arma poderosissima de luta. E' instrumento que, sobretudo, depende da mão que o vibra; se é o mal que o meneia, será uma clava que apenas damnifica e destróe; se ao contrario, é o bem que o dirige, a fé se reanima, a sciencia se exalta, a virtude se fortifica, o patriotismo se apura, o homem se engrandece. A imprensa, que permanentemente agita as consciencias, deixa um sulco mais fundo, mais duradouro que a palavra e o exemplo"

Neste trecho assignalava Brasilio Machado o que é, na verdade, a actuação da imprensa. Ella vale mais, muito 
mais do que a palavra e o exemplo, porque ella é a interpretação da realidade, isto é, a realidade através da intelligencia. E era Brasilio Machado quem, prevendo a força da imprensa aproveitada em máo sentido, quem lutava, desde o inicio de sua vida de jornalista, contra os perigos das orientações sem escrupulo e contra os males dos aventureiros da penna.

Frequentando os jornaes, desde muito moço, Brasilio Machado assignalou os males da imprensa, esses males que conhecemos, fomentadores da dissociação da vida, da incomprehensão politica e da desorientação cultural. E, no volume de sua argumentação, lembrava as campanhas de Jules Simon e de Béranger, por uma imprensa digna e seria.

Liberal convicto, sempre á frente, em todas as campanhas da liberdade, Brasilio Machado queria, isolando a imprensa dos máos designios, defender afinal a propria liberdade da imprensa que poderia morrer um dia pela corrupção da imprensa. Por isso, repito, era jornalista. Sabia, como nós hoje sabemos, que não ha liberdade onde não ha jornalismo, que não ha cultura onde não ha jornalismo, que não ha espirito civico onde não ha jornalismo.

Foi pelo jornal que Brasilio Machado começou a doutrinar. Foi pelo jornal que começou a combater pela liberdade do escravo, pela instrucção publica e pela religião. Para a sua intelligencia incançavel, o despedaçar da liberdade seria o mesmo que negar ao homem o direito de ser homem, isto é, o direito de ser o que elle deve ser.

Quando falava no Jury, em regra, ruidosamente victorioso, o que o empolgava e o transfigurava era o problema da liberdade do homem. Li, em seus guardados, a lista immensa dos absolvidos que conseguira. Procurava assim, em cada drama judiciario, em cada tragedia forense, o homem livre, restaurado em sua dignidade!

Por isso, ainda uma vez, repito: - era jornalista. o discurso que proferiu na installação do Instituto dos Advogados de S. Paulo, em novembro de 1891, numa das horas mais difficeis do Brasil, ficou como um brado angustioso da 
consciencia nacional. Em face do acto de Deodóro, o jornalista Brasilio Machado perguntava:- "que será da palavra, nesta escuridão profunda?!"

Por isso mesmo, por isso tudo, pedia e chamava por uma imprensa que fosse digna da liberdade e que jamais desse pretexto ás sanhas liberticidas.

Poucos jornalistas tiveram uma collaboração na imprensa, tão continuada e tão apaixonada. Era por onde o illustre mestre alcançava as distancias mais distantes; era por onde abria brecha nas resistencias mais resistentes e era por onde bradava por um Brasil livre, culto e feliz.

Quando, muito moço ainda, em 1881, numa das raras campanhas eleitoraes que emprehendeu, - apresentou-se candidato, dando como titulo, o titulo de jornalista. Tinha outros. Mas, como o Visconde de Chateaubriand, era este qualificativo que mais o honrava. Ora, seus adversarios necessitavam de um pretexto para combatel-o. E o pretexto foi esse: - Brasilio Machado, naquelle jornalismo pauperrimo de seu tempo, não era jornalista porque não auferia lucros de sua vida na imprensa!

Essa accusação pittoresca, foi feita em letras de fôrma. Marcava porem o jornalismo de Brasilio Machado. Em seu tempo, como agóra, em grande parte, o jornalista não tirava e nem podia tirar de seu trabalho, o pão de cada dia. Mas, o que elle desejava era fazer do jornal uma expressão de sua vida.

Só assim, na verdade, conseguia Brasilio Machado articular alguma cousa no desarticulado nacional. Criticando certos factos de administração, chamando a attenção dos administradores, emprehendendo campanhas vehementes em pról da instrucção publica, em favor de certos postulados politicos, affirmou-se, affirmando o seu paiz.

Já em 1879, no artigo programma do jornal "A Constituinte", que é um modelo jornalistico, pela precisão, clareza e vivacidade, escrevia Brasilio Machado, traduzindo o permanente ideal da democracia no Brasil: - "Trabalhando cuidadosamente pela educação nacional, preparando este 
povo para o goso de todas as liberdades politicas, - a Constituinte terá o seu ouvido attento ás palpitações do coração da sociedade, ás manifestações da consciencia publica e então de preferencia propugnára: - pela autonomia dos municipios, com a sua vida propria e independente. Pela completa descentralização administrativa e governamental, ficando as provincias entrelaçadas com a côrte, pelo unico laço da federação e a realização da promessa constitucional de duas camaras ás provincias"

E como lutou nesse jornal, pelo programma que traçou! E nessa luta não discrepou uma só vez, mantendo sempre a mesma linha de cordura e vehemencia, cordura e superioridade.

Nesse esforço para fixar alguma cousa, por entre mutacões bruscas de uma nacionalidade de formação inedita, numa paizagem aggressiva e mysteriosa, - o jornal é o trabalho de todos os dias, resoando para as grandes distancias, como a torre de Ménnon, ao contacto com a luz. Nesse esforço de todos os dias estava, desde o inicio de sua vida, Brasilio Machado até quando sentiu perto de si, na melancholia da velhice, os presagios da morte. O notavel jurista, o mestre indiscutido, o apostolo da educação, o orador sem rival, nunca quebrára a penna de jornalista e jamais sentiu em si diminuir a fé que cultuou, uma grande fé no destino previlegiado da imprensa pela construção paulista da nacionalidade!

ANTONIO DE ALCANTARA MACHADO, com o exemplo do avô e com o magnifico exemplo paterno em casa, foi logo, corajosamente, espiar a vida de perto. Envolvido por uma severa atmosphera cultural, fazendo suas traquinagens por entre os livros do pae e por entre os livros do avô, formou-se como intellectual, respirando e sentindo o valor dos volumes numerosos que enchiam as bibliothecas ancestraes. Conhecia-os todos, um por um e, com elles, documentos e cartas, recortes de jornaes, saboreando as velhas gravuras ou velhas photographias documentaes. Era, assim, precocemente, um sabichão, como o gato Amilcar que ronronava e 
fazia seus planos de sonhador incontrariado, no silencio augusto da livraria do subtil Anatole France.

Essa vida, que poderia ter feito delle uma flor de estufa, serviu, entanto, para maior equilibrio de seu espirito. Adquiriu, ao contacto com o avô e com o exemplo de seus paes, paulistas affirmativas, resistencia para supportar, na desordem brutal da sociedade contemporanea, os ataques que attingiam, em cheio, o idealismo de sua geração.

Sente-se, por isso, em Antonio, uma peculiaridade psychologica, que o desemelha de um certo modo, do avô, para quem a convicção não encontrava tropeços, nem, ao menos, na maneira de expressal-a. Antonio, com a alma aquecida, num ambiente austero e catholico, espiava um mundo de negação e de miserias. Brasilio Machado arrancava lagrimas do auditorio ou o deixava inteiramente encantado com os arroubos de sua eloquencia. Era uma força de convicção, construida por um mundo que não perdera ainda a sua convicção. Antonio, espiava uma paizagem diversa, muito diversa daquella que via em casa. Quando entra pelas arcadas da velha Faculdade, onde o avô era mestre eminente, onde o pae era mestre como o avô, o ambiente, permanentemente romantico, se dissolvia. Após um periodo de estudado septicismo, de negação elegante, no qual eram consagrados certos figurinos allemães e francezes, surgia um periodo de desplicencia e indifferença que se transformava num perigoso horror á tradição e á cultura.

Esse vento maligno vinha de longe. E Antonio sentiuo aggressivo e morno em seu rosto de adolescente. A eloquencia perdera a razão de ser. Os oradores recuavam das attitudes cicerenoeanas para assumirem o ar amaneirado dos velhos sofistas. A arte tornára-se vazia de conteudo, desprovida de sentido no excesso parnaziano, na estupidez naturalista, no avolumar dos copiadores desprovidos de imaginação e de sensibilidade. A grande guerra deixára afinal o mundo desapontado com os effeitos negativos do progresso. A principio, eram os mestres da negação ou da su- 
perficialidade naturalista. 0 criticismo chegára ao que certos escriptores denominam hoje "o furor de analyzar", aquelle furor tragico e desapontado que Machado de Assis, malicioso e incredulo, pôz magistralmente, nos versos primorosos da Mosca Azul.

A cultura ruia na Europa e minguava no Brasil. Baixa de ponto a olhos vistos. $\mathrm{O}$ romantismo fôra um momento da cultura nacional. O parnazianismo e o naturalismo tambem. Mas, quando Antonio, rapazola ainda naquelle despertar de alma que Papini descreveu com tanta fidelidade, começou suas leituras, - esbarrou meio desapontado, com esse estado de coisas, doentio e contraditorio. Entre o pensamento e a vida traçou-se um conflicto e Antonio apresentou-se como um escriptor ligeiramente sarcastico, com um sorriso de quem via as situações contraditorias. Por indole, por educação e formação moral - era um crente, um convicto. Em face do mundo e com uma leitura angustiada, tornou-se um lutador differente do avô. Seguia o mesmo caminho, mas levava uma carga diversa. Numa atmosphera inexpressiva e timida, Antonio procurou desafrontar os insultos atirados contra a intelligencia. Aquella pagina que, numa hora de nostalgia, escreveu na Europa, definia o seu espirito, o seu conflicto interior, ou melhor, o seu heroismo: - "quero morrer de chapéu na cabeça. Direi: O' não sabia que havia festa. E o meu desembaraço será tão grande que ninguem attentará na minha deselegancia.

Firmou-se por ahi, desde logo, como escriptor. Na claridade de uma nova geração que surgia, era uma luz differente pela sua precisão e suavidade. Foi apparecendo pelos jornaes como revelação cheia de seiva forte. Mal se apresentava, denunciava a nova phase cultural do espirito paulista. Vencia, com o seu estylo rapido e ironico, um periodo estenso de mediocridade mental. Era, emfim, um novo. Novo, mas não novidadeiro. Moderno, mas năo modernista. O seu espirito distendia-se agil pelo scenario da actualidade. Por esse scenario passava Antonio, fiel a si mesmo, por entre a exaltação mecanicista, pelo romantismo pro- 
gressista, pelo anarchismo literario, pela dissociação cubista. Não se desligava de modo algum, das suas raizes que mergulhavam fundo, por seculos, na historia de Piratininga. Dahi, as caracteristicas do espirito de Antonio: - um innovador tradicionalista. Novo estylo dentro das verdades vernaculas. E o humor, o risonho combate ao preconceito e á mundanidade artificiosa.

Estas qualidades definiram o jornalista. Para mim Antonio de Alcantara Machado era, acima de tudo, jornalista. Comecei a vel-o assim quando, em 1929, assumi a direcção do "S. Paulo Jornal". Elle disse-me em telegramma: - "parabens pelo altissimo posto que você conquistou!" 0 telegramma era designativo, porque Antonio sempre foi excessivamente discreto nos qualificativos. No entanto, elle dizia o que era, a direcção de um jornal de responsabilidades. E, depois, me confessou pessoalmente. O posto era, de facto, de grande responsabilidade. Um jornal, dizia-me, não é um armazem de seccos e molhados. E' elle um Moloch insaciavel que, como as feiticeiras de Maobeth, se alimentam das entranhas da vida.

Exercendo não sei porque, por mais de dez annos, as funcções de critico literario, acompanhei de perto a projecção de Antonio e verifiquei que toda a sua obra de chronista, de critico de arte e de theatro, de ensaista, de "conteur" e de politico, - era, afinal, uma das mais ricas, uma das mais finas, uma das mais expressivas obras do jornalismo. Era o jornal que o empolgava sempre e quem o visse na redacção do "Jornal do Commercio" (edição de S. Paulo), onde exerceu o cargo de director; ou na sua phase final, como director de "O Diario da Noite" do Rio de Janeiro, _ via-o agil e feliz, como um peixe dentro d'agua. E quando deixava, por alguns instantes, a secretaria da Bancada Paulista, nos carregados tempos da Constituinte e vinha a S. Paulo, como era delicioso ouvil-o, commentando!. O reporter ali estava, de olhos agudos nos acontecimentos e nos homens. O con- 
gresso rumorejando, indifferente ao orador commovido e pallido, deante da magestosa malicia do presidente Antonio Carlos.

Um dos maiores jornalistas do Brasil conheceu-lhe immediatamente a força do jovem escriptor e me dizia ao organizar a redacção de um jornal moderno: - "Pensei em Você. Mas, prefiro o Antonio. Você é partidario e metaphysico. Elle é realista e opportuno, um grande e moderno jornalista!

Aliás, ao repararmos toda a actividade cultural do Antonio vemos, na verdade, uma explendida vocação jornalistica. Aggripino Griecco disse que elle possuia uma grande bibliotheca em casa, mas ignorando as equações do egoismo e do orgulho, nas ruas é que sabia desofogar-se ás direitas, evitando a deformação livresca e procurando os seus heroes, não nos autores mortos, mas na vida vivissima das turbas.

De facto, no escriptor novo estava o autor singular e scintillante das reportagens definitivas. Senso critico preciso, finura e graça no julgamento, invejavel capacidade de improvisação, intelligencia avaliadora com força para enquadrar os factos em suas justas proporções. Antonio conquista renome com "Pathé Baby", que é uma obra digna de um Paul Morand, numa época em que não se conhecia ainda Paul Morand. E' fóra de qualquer excesso de apreciação, uma das mais perfeitas obras de jornalismo moderno. Depois, "Braz, Bexiga e Barra Funda", obra com a qual o chronista entra no ról dos grandes escriptores brasileiros. E sua collaboração tornou-se intensa nos jornaes. Artigos de fundo, definindo rumos, sueltos e commentarios, chronicas e criticas; óra o director, óra o redactor, óra o reporter. Factos do dia, um problemazinho municipal de um bairro esquecido ou, senão, um grave problema politico, a ordem constituida, a disputa parlamentar, problemas, economicos, educativos. 
Tinha uma visão aguda de seu tempo. Enxergava perto e enxergava longe. Viajado e estudioso, estava sempre em dia com os problemas que agitavam a sua geração. 0 Brasil não era propicio ás grandes campanhas ideologicas, mas necessitava de uma campanha para a valorização de intelligencia. Os tempos eram outros. Não tinhamos, como outras gerações tiveram, a campanha da independencia, a campanha liberal do $10^{\circ}$ Imperio, a campanha religiosa, a campanha paraguaya, a militar, a da libertação dos escravos e da republica. 0 civilismo fôra um movimento que intessára, mas, depois delle, nem a grande guerra conseguira dominar os espiritos. Porém, Antonio, como varias vezes me havia dito, percebia, com nitidez, o problema da construcção nacional, que continuava sempre com as mesmas ameaças. $O$ jornalismo devia, portanto, ter uma funç̧ão de totalidade. Não este ou aquelle problema, não este ou aquelle aspecto. Mas, a vida panorama, - tudo em funcção de todos, uma comprehensão envolvente e ajustada dos quadros da vida, porque assim haveria um possivel equilibrio brasileiro. $\mathrm{O}$ seu jornalismo ganha por isso em qualidade e em intensidade. Não fica nos jornaes. Mas é o director de jornaes de cultura e renovação, director de "Terra Roxa e outras Terras", da "Revista de Anthropophagia", da "Revista Nova"

A sua campanha, em 32, pelos jornaes e pelas estações de radio tiveram esse nobre e alto sentido e nellas suas linhas de paulista se illuminaram, nas trevas da revolução. Não viu detalhes. Viu o drama geral, o que significava $S$. Paulo na formação do paiz. Depois viu e viu bem perto de mim, o paiz ferido, procurando na constitucionalidade as ataduras urgentes para as feridas expostas.

Foi, para o Rio de Janeiro, como secretario da Bancada Paulista, olhando firme das alturas da Avenida Rio Branco, o Brasil que, difficultuosamente, renascia. Pouco tempo depois era director do "Diario da Noite", cheio de fervor e de enthusiasmo. Foi eleito deputado. Seus artigos politicos 
causavam então invulgar successo porque tocava as situações sociaes e as situações psychologicas. Estava, desse modo, vivendo tudo o que podia viver numa hora que era só de abnegação e sacrificio.

Perdemol-o infelizmente, ficando, diante de nós, um vacuo impreenchivel uma immensa saudade.

Em linhas rapidas são estes os dois nomes que o civismo da Associação recorda hoje. Recordação salutar e justa. Ha nomes que não devemos esquecer, que a imprensa de S. Paulo não deve esquecer. A nossa terra bem amada, dia a dia, cercada pelo cosmopolitismo sem entranhas e sem raizes, desprevenida pela insegurança de uma cultura dispersiva e mal esboçada deve manter sempre bem alto os exemplos de resistencia e de construcção. Brasilio Machado e Antonio de Alcantara Machado mostram, nas horas inquietas do Brasil, o esforço de solidariedade pela cultura, pela intelligencia e pelo sangue.

Ligados pelo sangue e ligados pelo espirito representam, no difficil repertorio nacional, a continuidade salutar do espirito paulista. E é com elles, como jornalistas exemplares que levaremos para frente a missão do jornalismo de S. Paulo, que é a de engrandecer a sua terra! 